\title{
KEYWORD INDEX TO VOLUME 6
}

agency 116

agricultural workers 269

anthropological political economy 269

anti-colonial struggles 64

assimilation 290

audience reception 436

black youth 97

Central Americans 376

Chicano prisoners 160

Chicano/Puerto Rican connection 64

childhood 252

citizenship 35

collaborative research methods 137

complementary and alternative medicine 398

creativity 418

criminal justice 11

criminalization 97

Cuban exile community 252

cubanidad 418

culture 398

deportation 35

detective fiction 376

detention 35

ethics pintas(os) 137

ethnic group 290

ethnic humor 436

farm labor 269

folk illness 398

gender 418

global Christianity 290

Hispanic female delinquency 116

human rights 160

hybridity 290

immigration 35

John Leguizamo 436
Latina girls 116

Latina/o literature 418

Latinas 11

Latino identity 376

Latino immigration 376

latino prison movement 64

Latino prisoners 160

Latino stereotypes 436

latino youth 97

Latinos 11, 35

madness 418

memory 252

new Latino South 376

Operation Pedro Pan 252

oral history methodology 137

Pintos 160

prison rebellions 64

prison research 116

prisoner rights 160

prisons 11

Protestants 290

public health 398

Puerto Ricans 269

race 418

race and crime 97

racial discrimination 35

radical pedagogy 64

resistance 116

Salvadoran-American 376

social movements 64

social protest 269

susto 398

traditional medicine 398

trauma 252

workforce 290

youth studies 116 